\title{
Case Report: Congenital nasal pyriform aperture stenosis with holoprosencephaly: Diagnosis and surgical management
}

Melcol Hailu Yilala ( $\nabla$ melcol.hailu@aau.edu.et)

Addis Ababa University, College of Health Sciences

Dawit Kibebew Dibaba

Addis Ababa University,College of Health Sciences

Messay Gebrekidan

Minilik II Hospital

Dessalegn Tilahun

Addis Ababa University, College of Health Sciences

\section{Case Report}

Keywords: Neonate, CNPAS, Choanal atresia, Holoprosencephaly, Premaxillary dysgenesis, Hypertelorism

Posted Date: October 4th, 2021

DOI: https://doi.org/10.21203/rs.3.rs-955028/v1

License: (a) (i) This work is licensed under a Creative Commons Attribution 4.0 International License. Read Full License 


\section{Abstract}

Congenital nasal pyriform aperture stenosis (CNPAS) is a rare cause of neonatal nasal obstruction that clinically mimics choanal atresia. It occurs as a result of abnormal development of primary palate and maxilla, either in isolation or in association with other anomalies. Differentiation between CNSPAS and choanal atresia is critical as management approachers are quite different from one another. Diagnosis can be made clinically and with characteristics CT findings. Management options include both conservative and surgical approaches depending on the patient's initial condition. Here is reported a case of 33 days infant who was admitted to our NICU with a working diagnosis of CNPAS after she presented with two days of fast breathing and failure to suckle, managed surgically and discharged improved.

\section{Introduction}

Congenital nasal pyriform aperture stenosis (CNPAS) is a rare and unusual cause of neonatal nasal obstruction clinically mimicking bilateral choanal atresia. 1,3,6 The first clinical case was reported by Brown, et al in 1989. ${ }^{9}$ CNPAS is a result of abnormal development of the primary palate and bony overgrown of nasal process of maxilla that produces symptoms and signs of nasal obstruction in neonates and infants. ${ }^{2}$ CNPAS may occur in isolation or in association with central mega-incisor and the holoprosencephaly spectrum of congenital midline lesion. 2,5,7,11 Differentiation between CNSPAS and choanal atresia is critical as management approachers are quite different from one another. Diagnosis is based on clinical findings and confirmed by characteristics CT findings, the most helpful measurement being the width of the piriform aperture which is distance between the medial aspects of the maxillae at the level of the inferior meatus, as measured by axial CT. ${ }^{3,5,6}$ CNPAS cases can be managed both with conservative approach and surgically depending on the severity of symptoms and stenosis at initial presentation. ${ }^{4}$ Here we report the first case of CNPAS from Ethiopia, a 33 days old infant who presented to our facility at the age of 48 hours with symptoms of failure to suckle and fast breathing with characteristics CT findings of CNPAS and central mega incisor.

\section{Case Report}

History- 33 days old female infant, born to a Para II mother presented with failure to suckle and fast breathing since the second day she was born. She was born mature, weighed $3 \mathrm{KG}$, cried immediately and delivery was uneventful.

Physical Examination- she was cyanotic on admission, PR, 150 beats per minute, RR- 58 breathes per minute, PSo2- 90-92\% with face mask ventilation. She has hypertelorism, flat nasal bridge, high arched palate and single central incisor on head and neck examination. Number 06 NGT insertion was impossible past one centimeter beyond the nasal alae bilaterally.

She as no auricular malformation, Chest was clear with comparable air entry bilaterally. No murmur or gallop was heard on CVS examination. There was no palpable abdominal area swelling nor there was 
visible. genital area abnormality. She was alert and irritable.

CT imaging- pyriform aperture is narrowed to $4.2 \mathrm{~mm}$ with thickened nasal process of the maxilla and medial angulation at the level of inferior meatus. The posterior chonchae is patent with NG tube seen traversing. There is a central single mega incisor which as a rule an indication to see for other features of holoprosencephaly. On the brain scan there is partial volume loss and thick gyration of the anterior frontal lobe with absent corpus callosum. There is widened anterior half falx. There is also concomitant hemorrhage seen in the body and occipital horn of the right lateral ventricle which is not commonly noticed in CPANS cases. The opic chiasm, hypothalamic area and sellar regions with the pitutary gland are unremarakable on the CT scan.

Echocardopraphy and abdominal untrasound results were unremarkable.

TFT, RFT, LFT were also with in their normal limits.

Management- (Surgical) our patient was taken to the operation room after written informed consent was obtained from her mother, general anesthesia was given via orotrachial intubation, nasal and perioral area was cleaned with povidone iodine she was draped, two centimeter transverse sub-labial incision was made, periosteum was identified and carefully elevated with periosteal elevator until the nasal spine and maxillary processes were visible and the entire pyriform aperture was exposed, narrow pyriform aperture was drilled using 2 millimeter diamond burr laterally both ways and deep into the cavity until it was wide enough to accommodate an endotracheal tube with 3.5 inner diameter each nasal cavity. Finally periosteum was replaced, sub-labilal incision was closed using absorbable suture, stent was placed In each nostril and fixed with each other with silk suture, patient was allowed to wake up, extuabted and transferred to PACU with stable vital signs.

Postoperative Course-Stent was removed on her fifth postoperative day, she is off face mask oxygen support, no feeding interruption, doesn't become pale while suckling, has no fast breathing.

\section{Discussion}

Congenital nasal piriform aperture stenosis (CNPAS) is an uncommon cause of nasal obstruction in neonates which clinically mimics choanal atresia. ${ }^{1,3}$ It occurs at a frequency of approximately one-fifth to one-third of choanal atresia. ${ }^{6}$ CNPAS is related to abnormal development of the palate which can be explained by a deficiency of the fused medial nasal prominences with subsequent faulty development of a small triangular primary palate, abnormal incisors, and a narrow anterior nasal cavity. ${ }^{2,3,5}$ Associations

with mid facial and mid brain abnormalities and Holoprosencephaly has been currently identified. 5,7,8,11 Hypertelorism and a flat nasal bridge are other clinical features of premaxillary dysgenesis associated with holoprosencephaly. ${ }^{5} \mathrm{~A}$ developmental deficiency of the incisive os is hypothesized to underlie the triangular plate, the narrow inferior portion of the nasal cavity, and the associated central maxillary megaincisor, which is seen in $60 \%$ of cases. ${ }^{2,3}$ 
Two theories about the pathogenesis of CNPAS have been reported: First- a deficiency of the primary palate that would also explain the abnormal incisors, narrow inferior portion of the nasal cavity, and triangular palate and second- bone overgrowth in the nasal process of the maxilla. ${ }^{2,3,6}$

Clinically, CNPAS can mimic choanal atresia. Infants present with respiratory distress, either at birth or within the first few months of life. ${ }^{6}$ The breathing problems may be triggered by an upper respiratory infection that further compromises an already narrowed nasal passage. ${ }^{4,5,6}$ As in patients with choanal atresia, in patients with CNPAS, a nasogastric tube may be difficult to pass. ${ }^{4}$ Symptoms may be more pronounced during feeding. Unlike choanal atresia, in which a bone and/or membranous plate obstructs the posterior nasal cavity, CNPAS is a narrowed but patent anterior nasal cavity. $6,7,8$

The diagnosis of CNPAS can be suggested by the physical finding of a very narrow nasal inlet, but the diagnosis is made with CT of the nasal cavity. ${ }^{2,4,6}$ Typical imaging findings of CNPAS consist of a narrowed bone inlet, triangle- shaped palate, bone overgrowth in the nasal process of the maxilla, and abnormal dentition. The presence of a bone ridge along the inferior aspect of the palate, as well as dental anomalies involving the incisors, strongly suggests the diagnosis. Affected CT- parameters include reduced width of pyriform aperture, cross-sectional area of nasal cavity and width of choana while height of nasal cavity and cross-sectional area of choanae remain unaffected. ${ }^{6}$ Among the parameters mentioned, the width of pyriform aperture being measured from one end medial aspect of maxilla to another at the live of inferior meatus remains the most helpful one. ${ }^{6}$

The pyriform aperture is the narrowest part of the normal nasal airway, and small changes in its crosssectional area can result in a significant increase in nasal airway resistance. Anatomically, the pyriform aperture is a pear-shaped bony inlet of the nose bounded laterally by the nasal processes of the maxilla, inferiorly by the junction of the horizontal processes of the maxilla and the anterior nasal spine and superiorly by the nasal bones. ${ }^{5,7}$ The maxillary spines mark the inferior margin of the pyriform aperture (Figure 6). ${ }^{7}$ The posterior choanae, or the opening between the nasal cavity and the nasopharynx, should be at least $0.34 \mathrm{~cm}$ in children under 2 years in our patient it reaches $4.3 \mathrm{~cm}$.

Regarding our case the the pyriform aperture is narrowed to $4.2 \mathrm{~mm}$ with thickened nasal process of the maxilla and medial angulation at the level of inferior meatus. The normal caliber is usually greater than $11 \mathrm{~mm}$ but most literatures consider narrowing if it is less than $8 \mathrm{~mm}$. The posterior chonchae is patent with NG tube seen traversing. There is a central single mega incissor which as a rule an indication to see for other features of holoprosencephaly. On the brain scan there is partial volume loss and thick gyration of the anterior frontal lobe with absent corpus callosum. There is widened anterior half falx. There is also concomitant hemorrhage seen in the body and occipital horn of the right lateral ventricle which is not commonly noticed in CPANS cases. The opic chiasm, hypothalamic area and sellar regions with the pitutary gland are unremarakable on the CT scan.

For CT diagnosis, good, thin section $(1.5 \mathrm{~mm})$ images should be obtained with axial sections parallel to the anterior hard palate, as apparent narrowing may be caused by oblique imaging. ${ }^{2}$ The normal range of 
the width of pyriform sinus in the age group of $0-6$ months is $8.8-17.2 \mathrm{~mm}$ (median width $13.5 \mathrm{~mm}$ ). A pyriform aperture width $<3 \mathrm{~mm}$, or a whole pyriform aperture width $<8 \mathrm{~mm}$, in a term infant confirms the diagnosis of CNPAS. ${ }^{2,6}$ In the study conducted by Belden et al, performed using the CT scans of six infants with CNPAS over 6 years, all six patients had a pyriform aperture width of less than $8 \mathrm{~mm} .{ }^{9}$ This single measurement is useful in making the diagnosis of CNPAS. The width of the pyriform aperture is taken as the total width between the medial aspects of the maxilla at the level of the inferior meatus. ${ }^{1}$ In addition, the area of the pyriform aperture can be obtained on coronal images by tracing the bony outline. The height of the nasal cavity is essentially normal in patients with CNPAS. Thus, CNPAS can be described as an anomaly that results in narrowing of the nasal cavity that is most severe in its anterior and inferior aspects.

Holoprosencephaly is commonly seen in association with patients with CPAS and our case has a semilobar type of holoprosencepaly with ageneisis of the corpus callosum. The basisphenoid region appears intact and no herniation of the brain parenchyma noted which in few of the cases encepahlocele is seen.

Management of CNSPAS includes, initial airway establishment using McGovern nipple or endotracheal intubation depending on the severity of symptoms at presentation. ${ }^{4,11}$ Mild cases can be managed more conservatively with topical decongestants and placement of sialistic stents. Furthermore mild cases can also be treated with securing the airway patent by using oral airways or McGovern Nipple., ${ }^{4,9}$ Pyriform aperture width greater than $5 \mathrm{~mm}$ is a good indicator of successful conservative management. ${ }^{4,10}$ However, moderate to severe cases at presentation, those with pyriform aperture width less than $5 \mathrm{~mm}$ and failed conservative management cases can be managed surgically. Surgical treatment is usually reserved for those with severe stenosis and failed conservative treatments. ${ }^{4,9,10}$ This includes widening and reshaping of stenotic area to create adequate airway passage and usually has good postoperative results, ${ }^{4,9,10}$ while whether to put a stent postoperatively still remains a matter of controversy. Inline with the currently accepted management for severe cases, our patient was treated surgically. (Figure 6-12).

\section{Conclusion}

Congenital nasal pyriform aperture stenosis (CNPAS) is a rare, treatable and often missed cause of neonatal upper airway obstruction. Thorough clinical evaluation, high index of suspicion and sound radiologic knowledge are required to come to a final diagnosis and management which makes the whole process a multidisciplinary approach. Prompt diagnosis and appropriate management are mandatory as neonates are obligate intranasal breathers.

\section{Declarations}

\section{Sources of support}

Nil 


\section{Declaration of competing interest}

None

Consent: The mother of the new born has been informed and legal written consent was taken before proceeding with the surgery. Furthermore, consent was obtained to take intraoperative pictures, write the case report, and publish it.

\section{References}

1. Rao A, Godehal SM, Patil AR, Mallarajapatna G, Nandikoor S, Hariharan M. Congenital nasal pyriform aperture stenosis: a rare cause of neonatal nasal airway obstruction. BJR Case Rep 2015;1:20150006.

2. Thomas EM, Gibikote S, Panwar JS, Mathew J. Congenital nasal pyriform aperture stenosis: a rare cause of nasal airway obstruction in a neo- nate. Indian J Radiol Imaging 2010; 20: 266-8. doi: 10.4103/0971-3026.73539

3. Baxter DJ, Shroff MM: Developmental maxillofacial anomalies. Semin Ultrasound Comput Tomogr Magn Res 32(6):555-568, 2011.

4. Sesenna E, Leporati M, Brevi B, Oretti G, Ferri A. Congenital nasal pyriform aperture stenosis: diagnosis and management. Ital J Pediatr 2012; 38: 28. doi: 10.1186/1824-7288-38-28

5. Van Den Abbeele T, Triglia JM, Francois M, et al: Congenital nasal pyriform aperture stenosis: diagnosis and management of 20 cases. Ann Otol Rhinol Laryngol 110:70, 2001.

6. Belden CJ, Mancuso AA, Schmalfuss IM: CT features of congenital nasal piriform aperture stenosis: initial experience. Radiology 213: 495, 1999.

7. DeMyer W, Zeman W, Palmer CD: Familial alobar holoprosen- cephaly (arhinencephaly) with median cleft lip and palate. Report of patient with 46 chromosomes. Neurology 13:913, 1963.

8. Arlis H, Ward RF: Congenital nasal pyriform aperture stenosis. Isolated abnormality vs developmental field defect. Arch Otolaryngol Head Neck Surg 118:989, 1992.

9. Brown OE, Myer CM, 3rd, Manning SC: Congenital nasal pyriform aperture stenosis. Laryngoscope 99:86, 1989.

10. Visvanathan V, Wynne DM: Congenital nasal pyriform aperture stenosis: a report of 10 cases and literature review. Int J Pediatr Otorhinolaryngo/ 76(1):28, 2012.

11. Johnson P, Smith M. Congenital nasal pyriform aperture stenosis. Internet J Otorhinolaryngol 2009

\section{Figures}




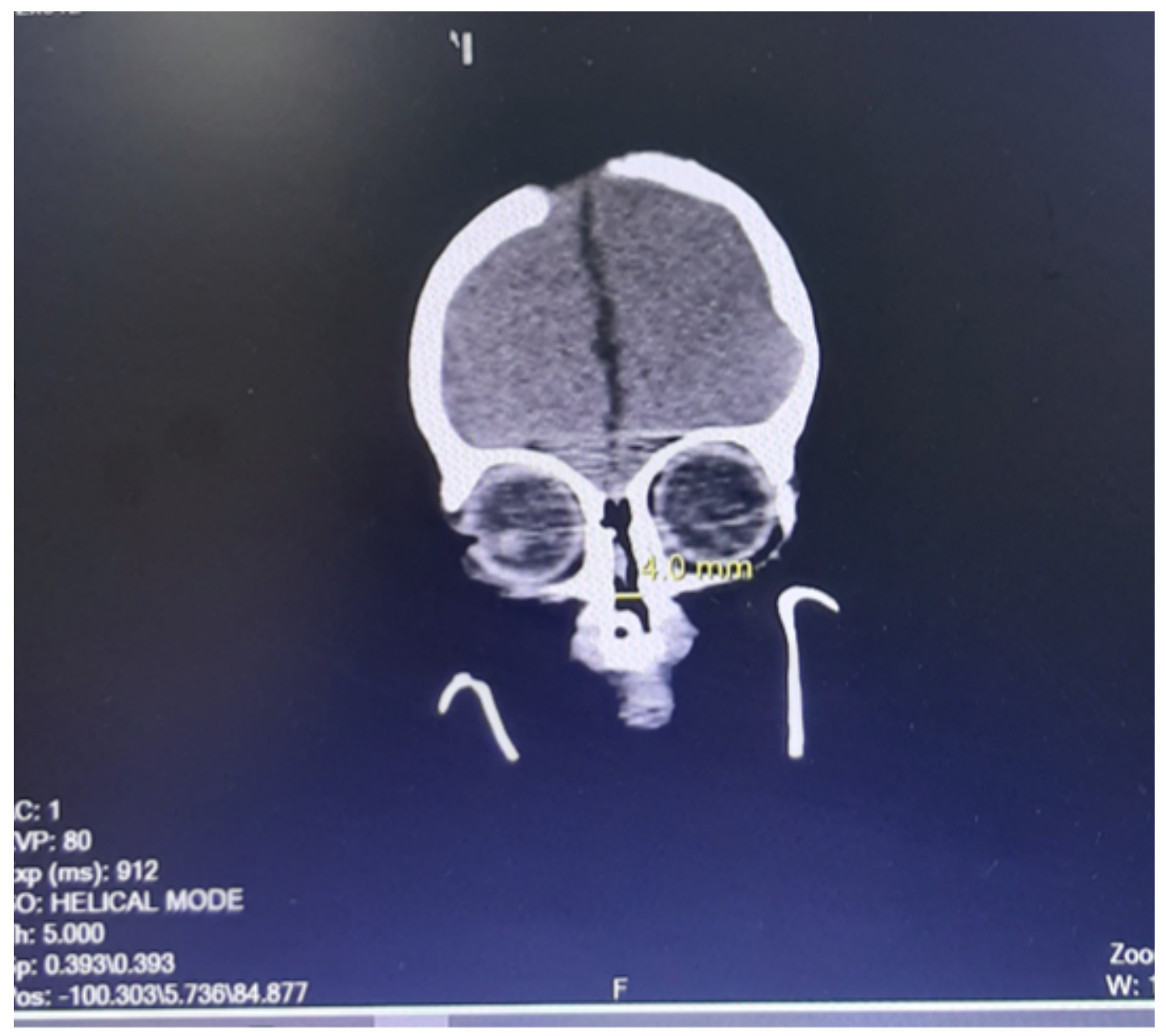

\section{FIGURE 1- CORONAL CT SHOWING NARROW PYRIFORM APERTURE MEASURING 4.2MM}

Figure 1

Coronal CT showing narrow pyriform aperture measuring $4.2 \mathrm{~mm}$ 


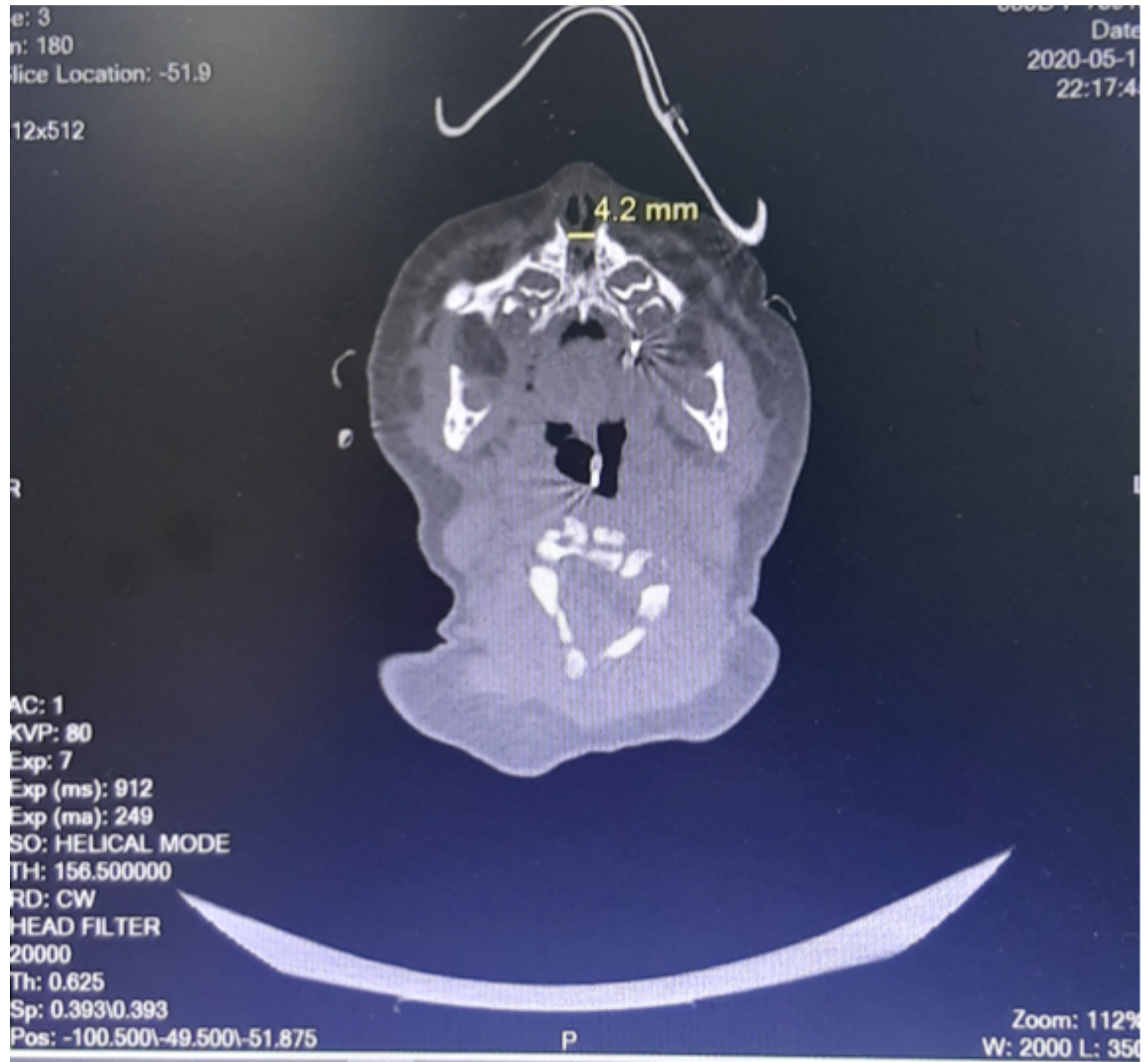

\section{FIGURE 2- AXIAL CT SHOWING NARROW PYRI- FORM APERTURE MEASURING 4.2MM}

Figure 2

Axial CT showing narrow pyriform aperture measuring $4.2 \mathrm{~mm}$ 


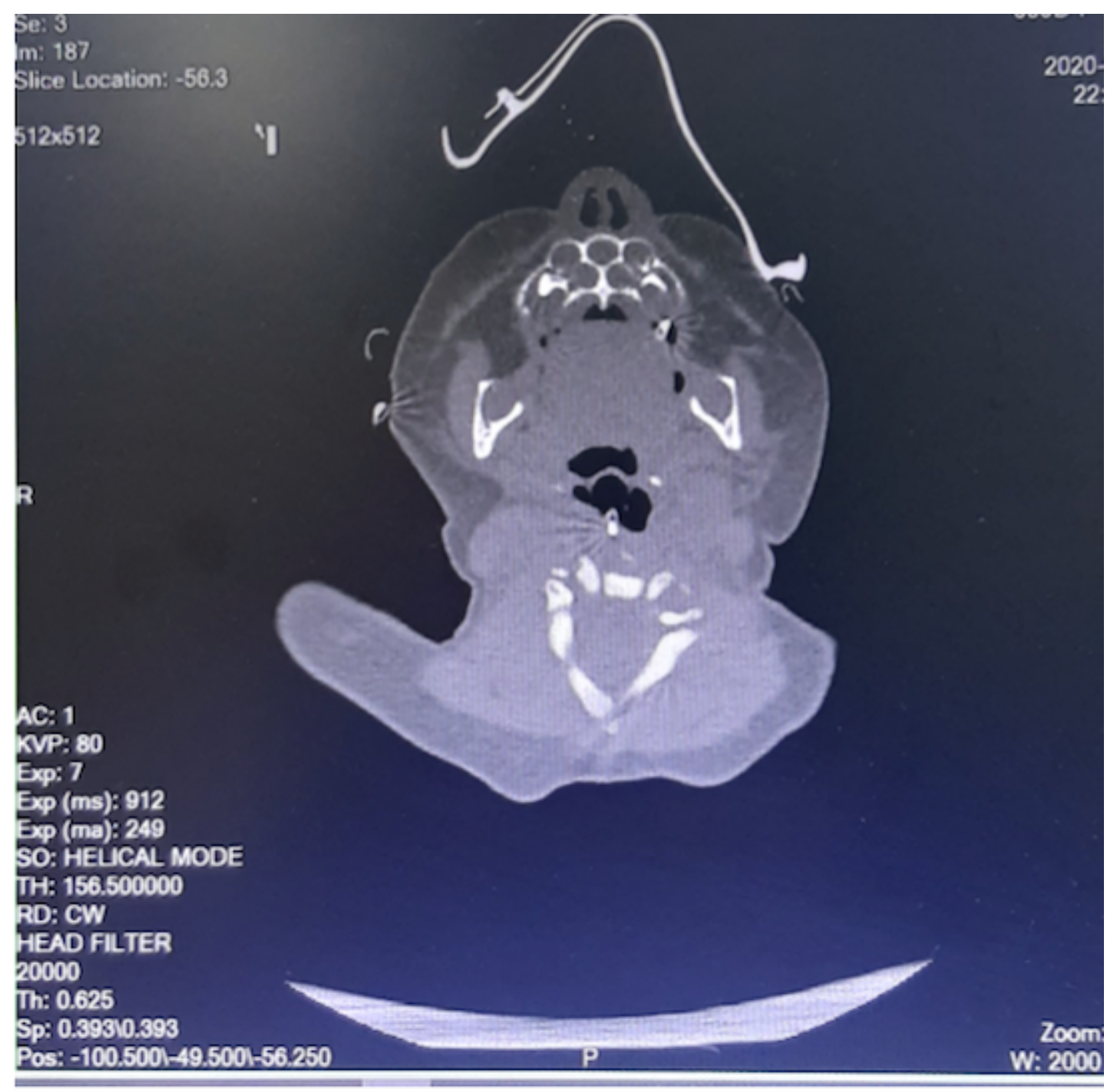

FIGURE 3- AXIAL CT SHOWING CENTRAL MEGA INCISOR AND NARROW TRIANGULAR HARD PALATE

Figure 3

Axial CT showing central mega incisor and narrow triangular hard palate 


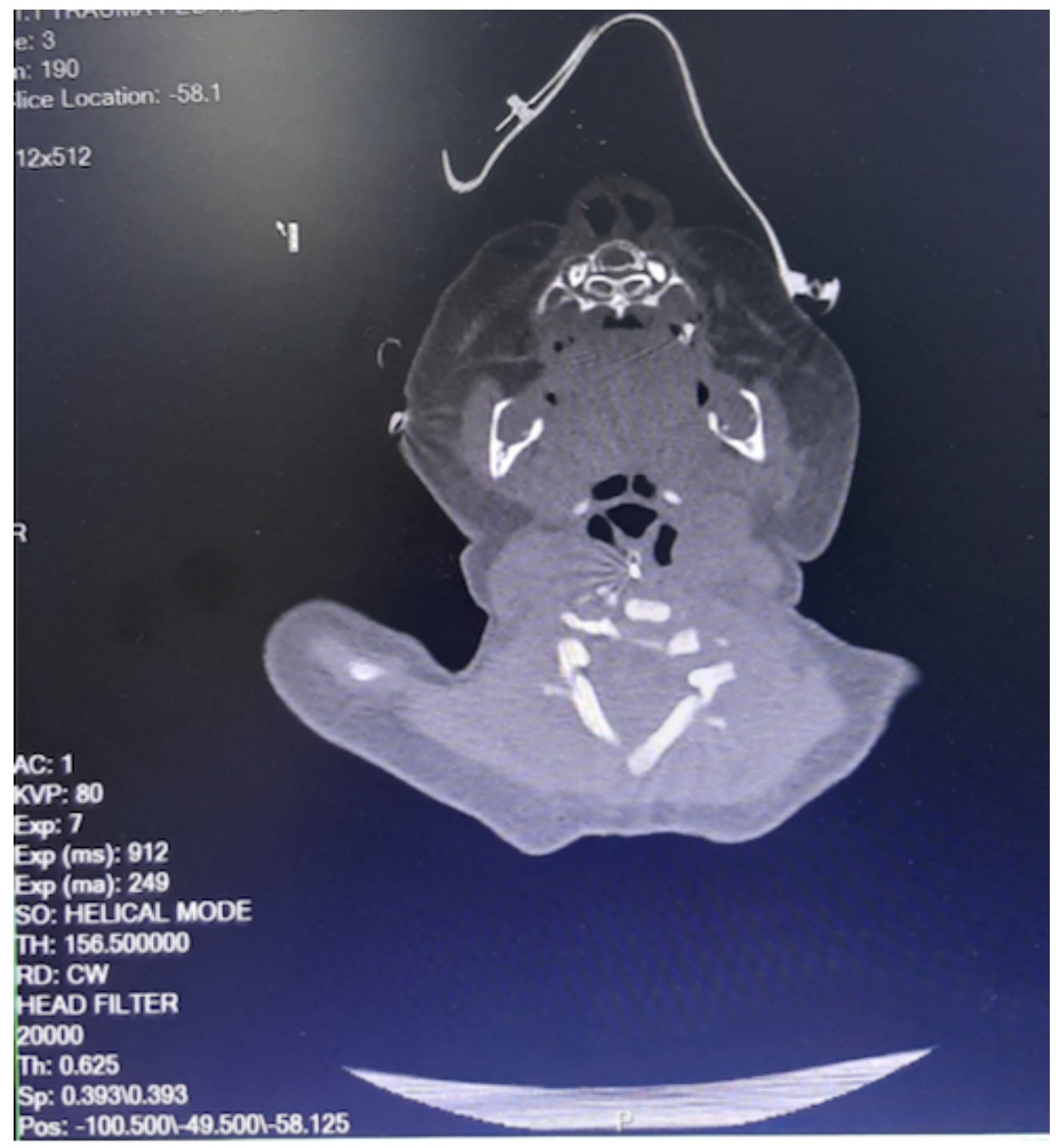

\section{FIGURE 4. AXIAL CT SHOWING CENTRAL MEGA INCISOR AND NARROW TRIANGULAR HARD PALATE}

Figure 4

Axial CT showing central mega incisor and narrow triangular hard palate 


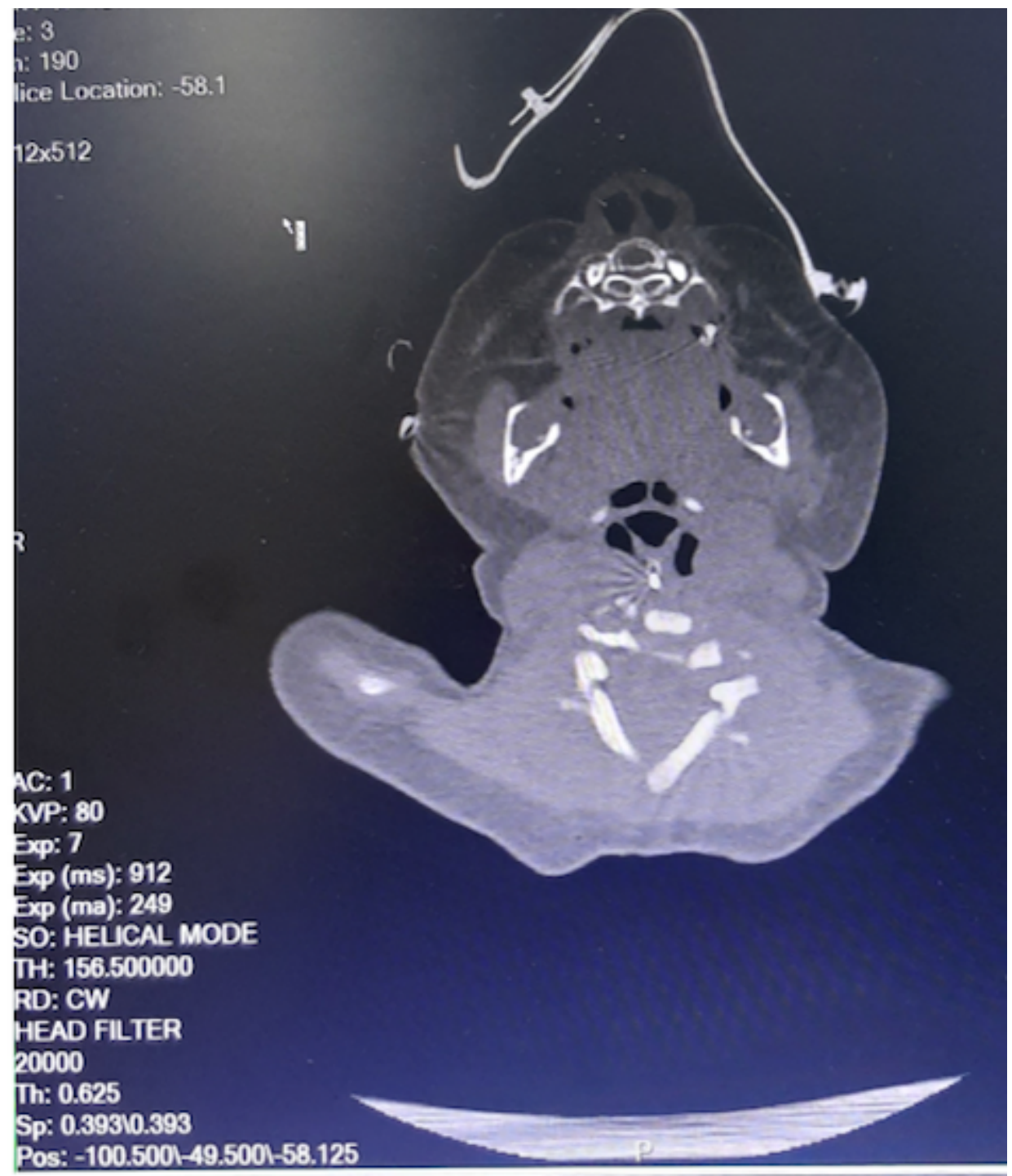

FIGURE 5- AXIAL CT SHOWING CENTRAL MEGA INCISOR AND NARROW TRIANGULAR HARD PALATE

Figure 5

Axial CT showing central mega incisor and narrow triangular hard palate 


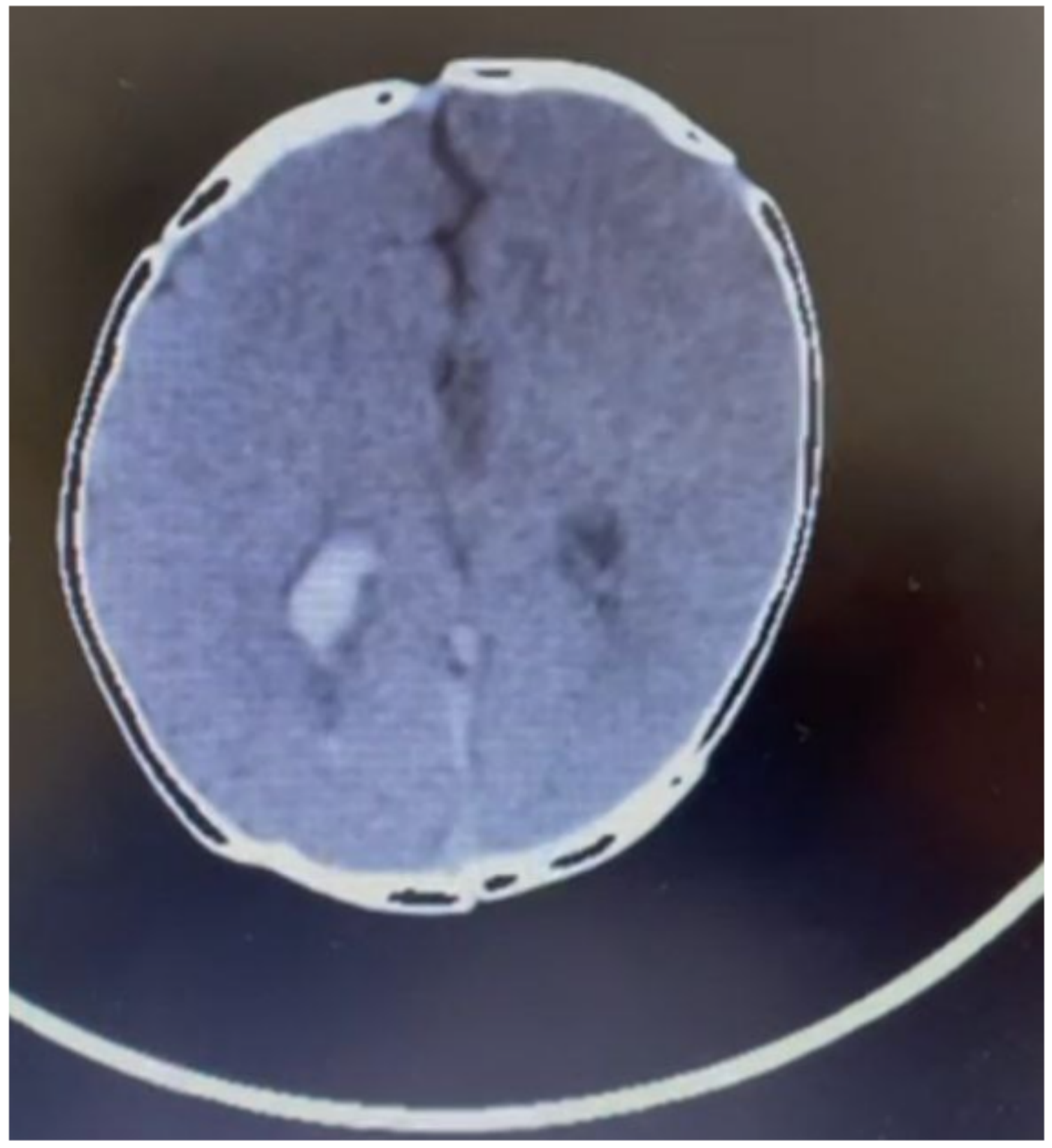

\section{FIGURE 6- AXIAL CT SHOWING RIGHT INTRA- VENTRICULAR HEMORRHAGE}

Figure 6

Axial CT showing right intra-ventricular hemorrhage 


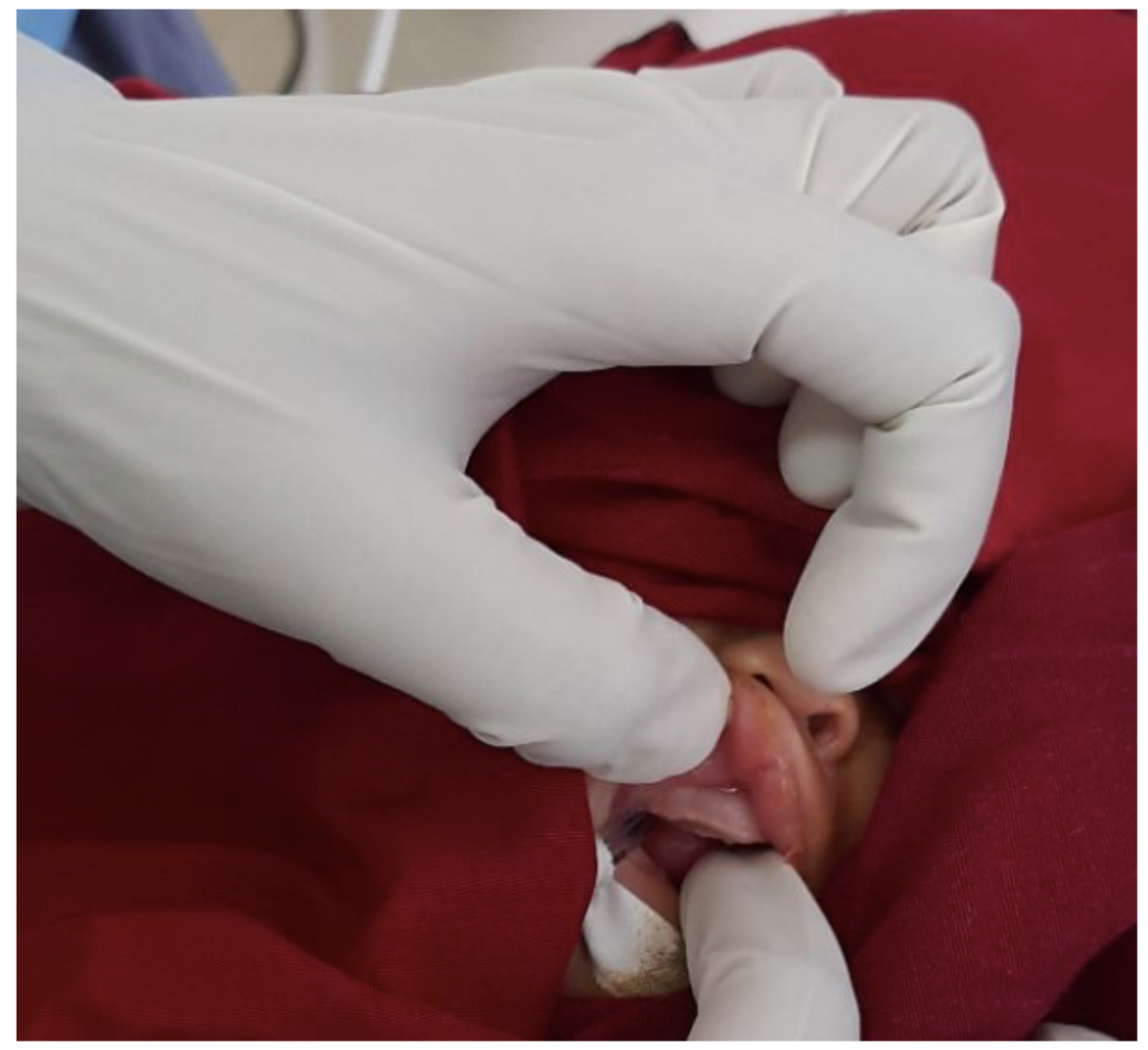

\section{FIGURE 7- PREOPERATIVE PALPATION}

Figure 7

Preoperative palpation 


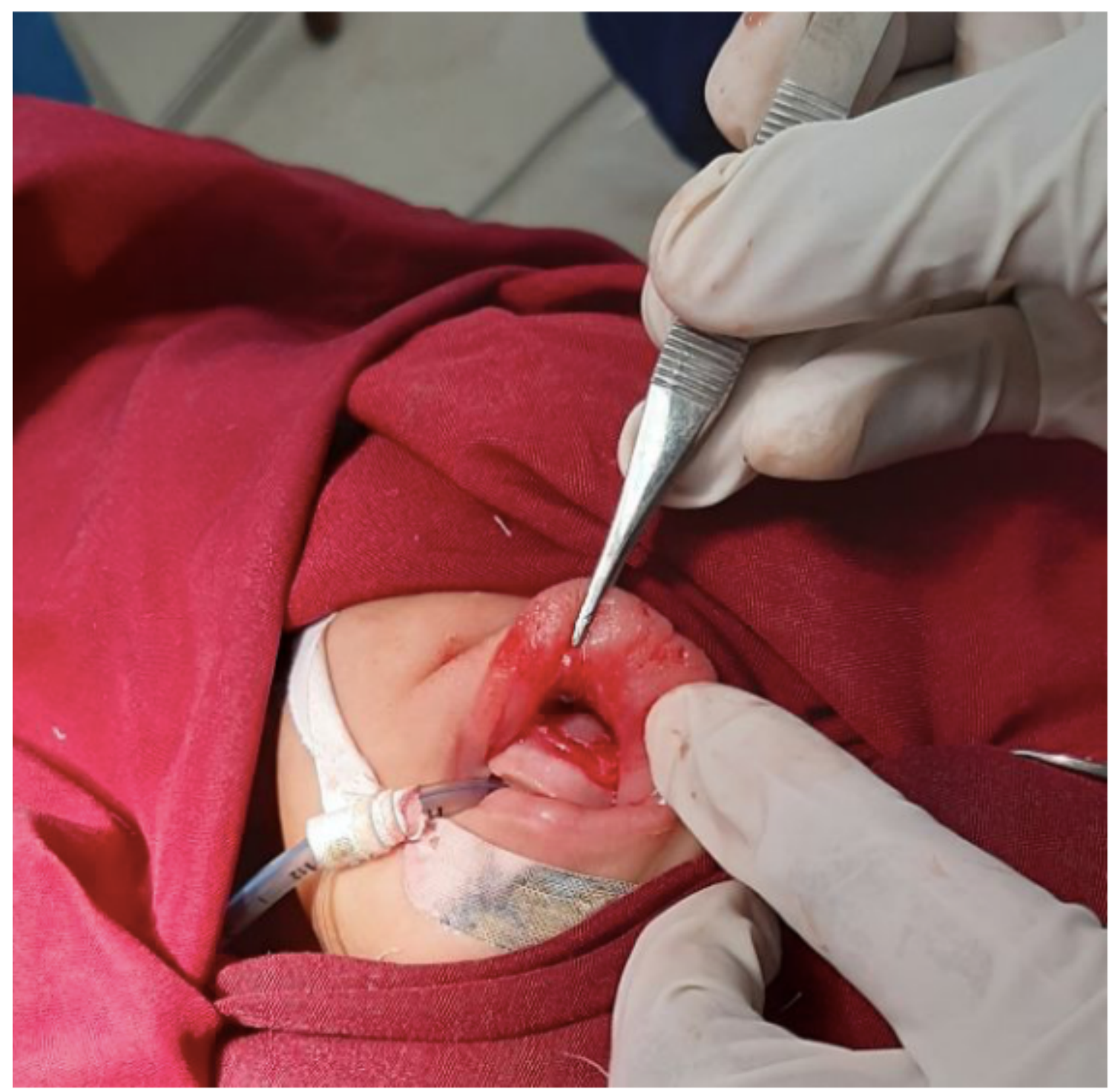

\section{FIGURE 8- SUBLABIAL INCISION}

\section{Figure 8}

Sublabial incision 


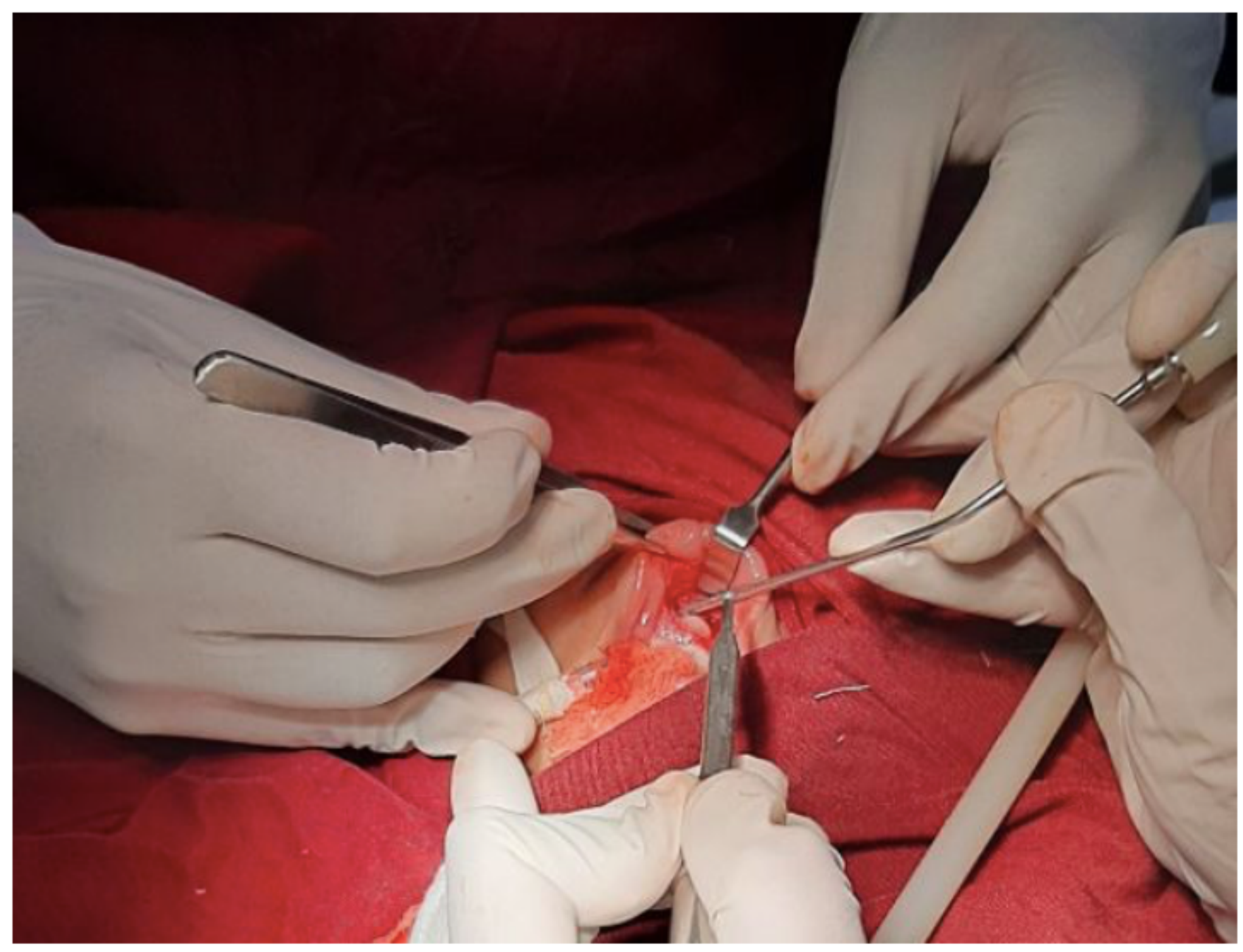

FIGURE 9- INTRAOPERATIVE PICTURE OF NARROW PYRIFORM APERTURE

Figure 9

intraoperative picture of narrow pyriform Aperture 


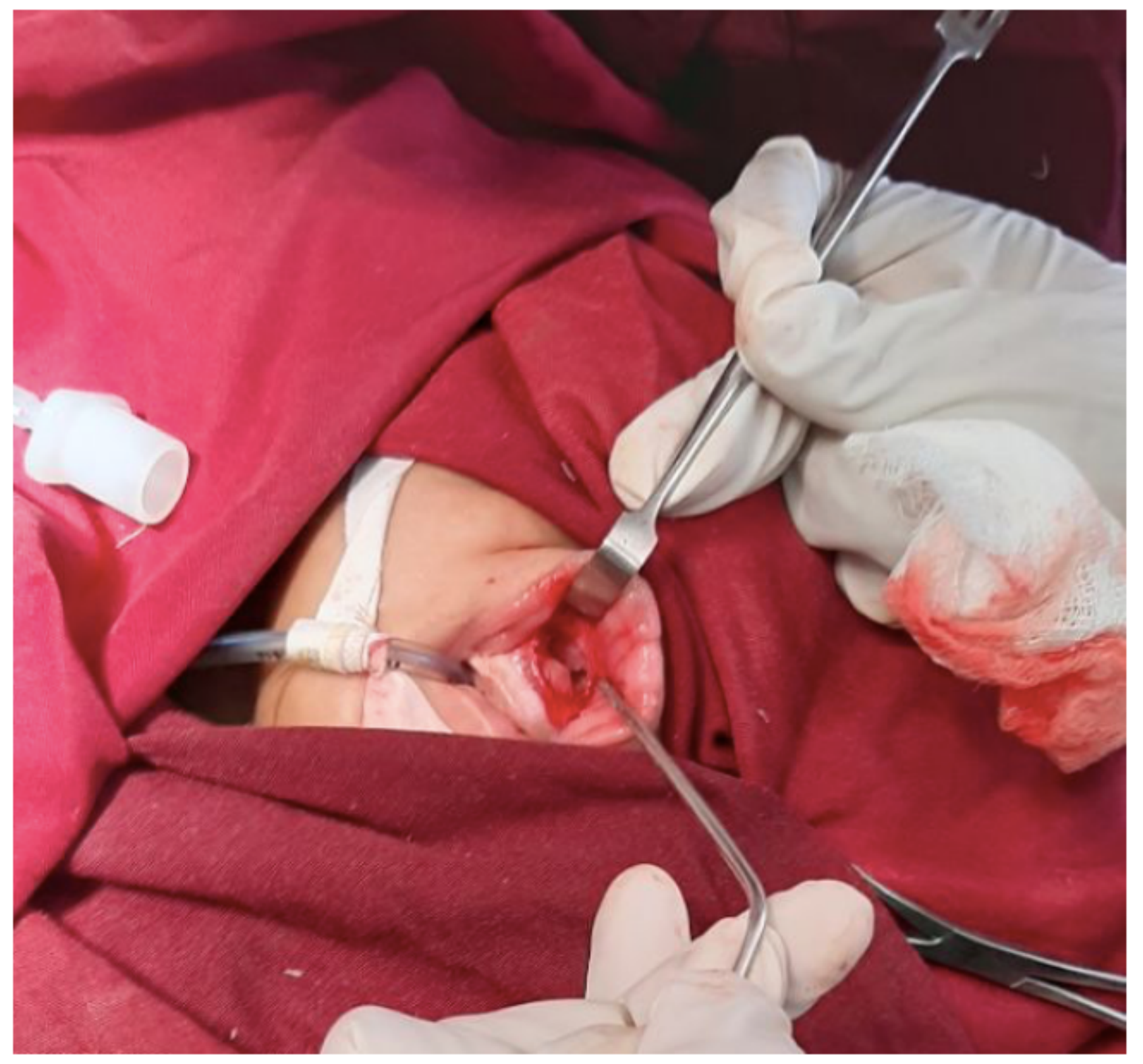

\section{FIGURE 10- INTRAOPERATIVE PICTURE OF NARROW PYRIFORM APERTURE}

Figure 10

intraoperative picture of narrow pyriform Aperture 


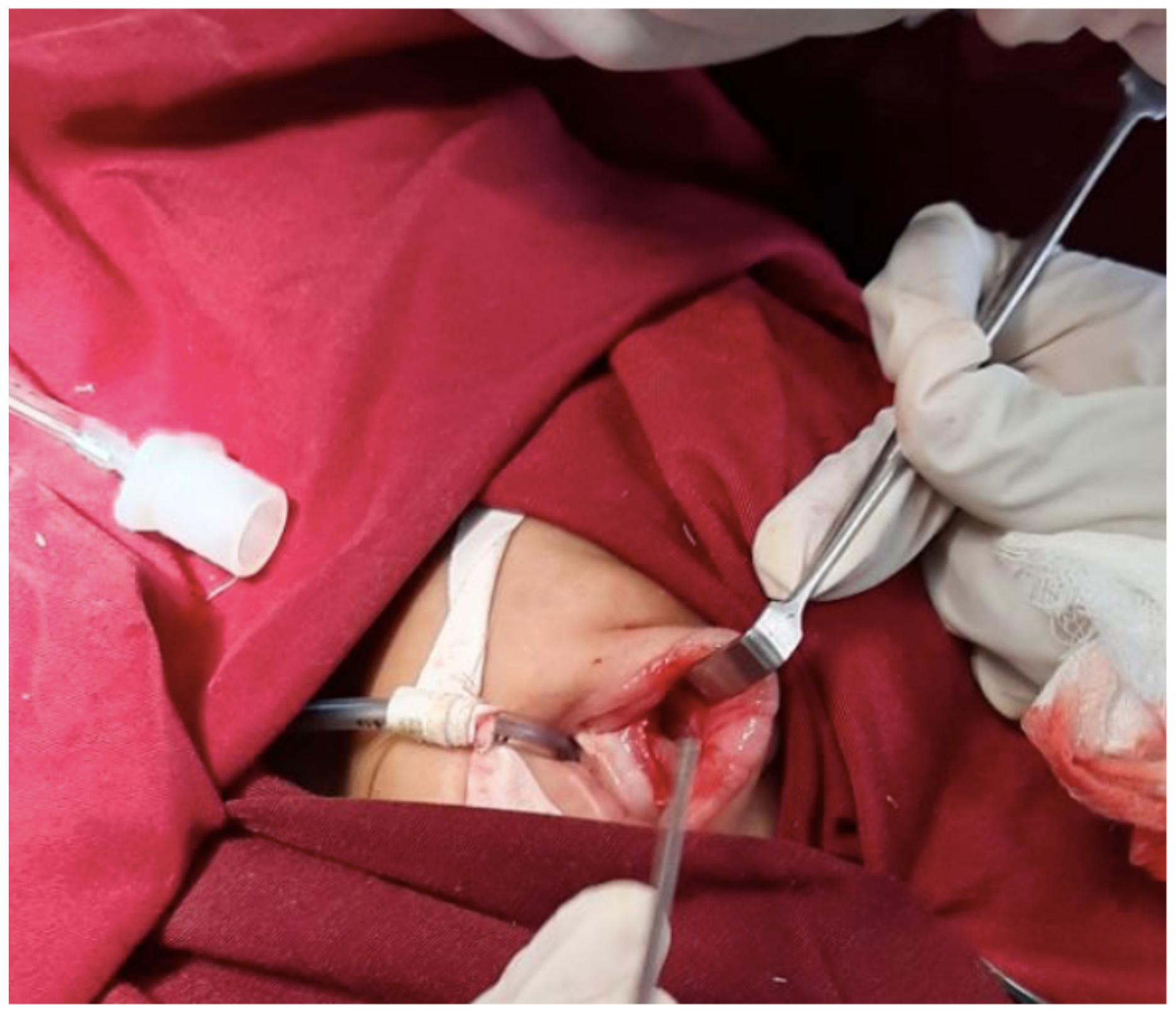

FIGURE 11- INTRAOPERATIVE PICTURE OF NARROW PYRIFORM APERTURE

Figure 11

intraoperative picture of narrow pyriform Aperture 


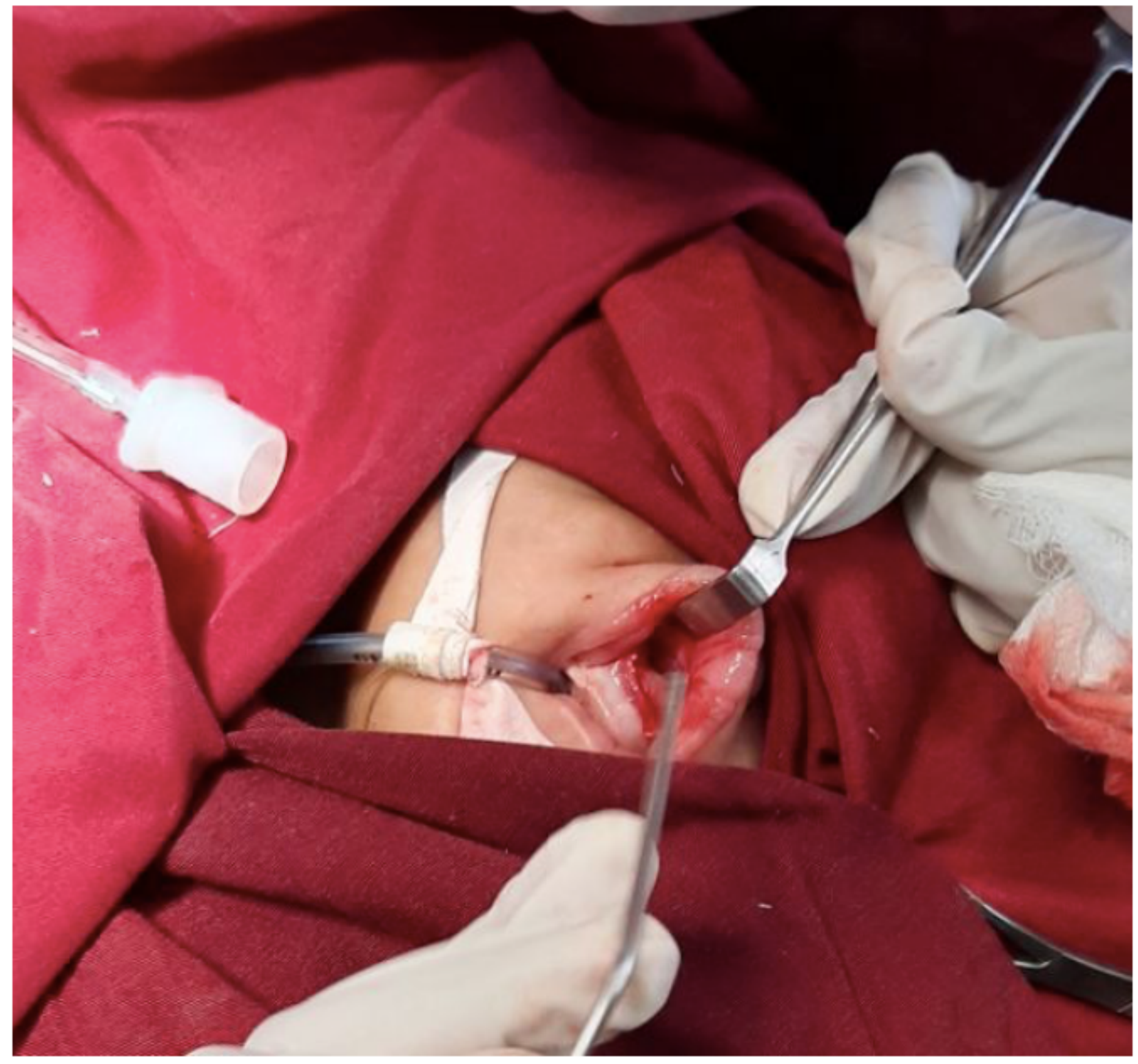

\section{FIGURE 12- INTRAOPERATIVE PICTURE OF NARROW PYRIFORM APERTURE}

Figure 12

intraoperative picture of narrow pyriform Aperture 


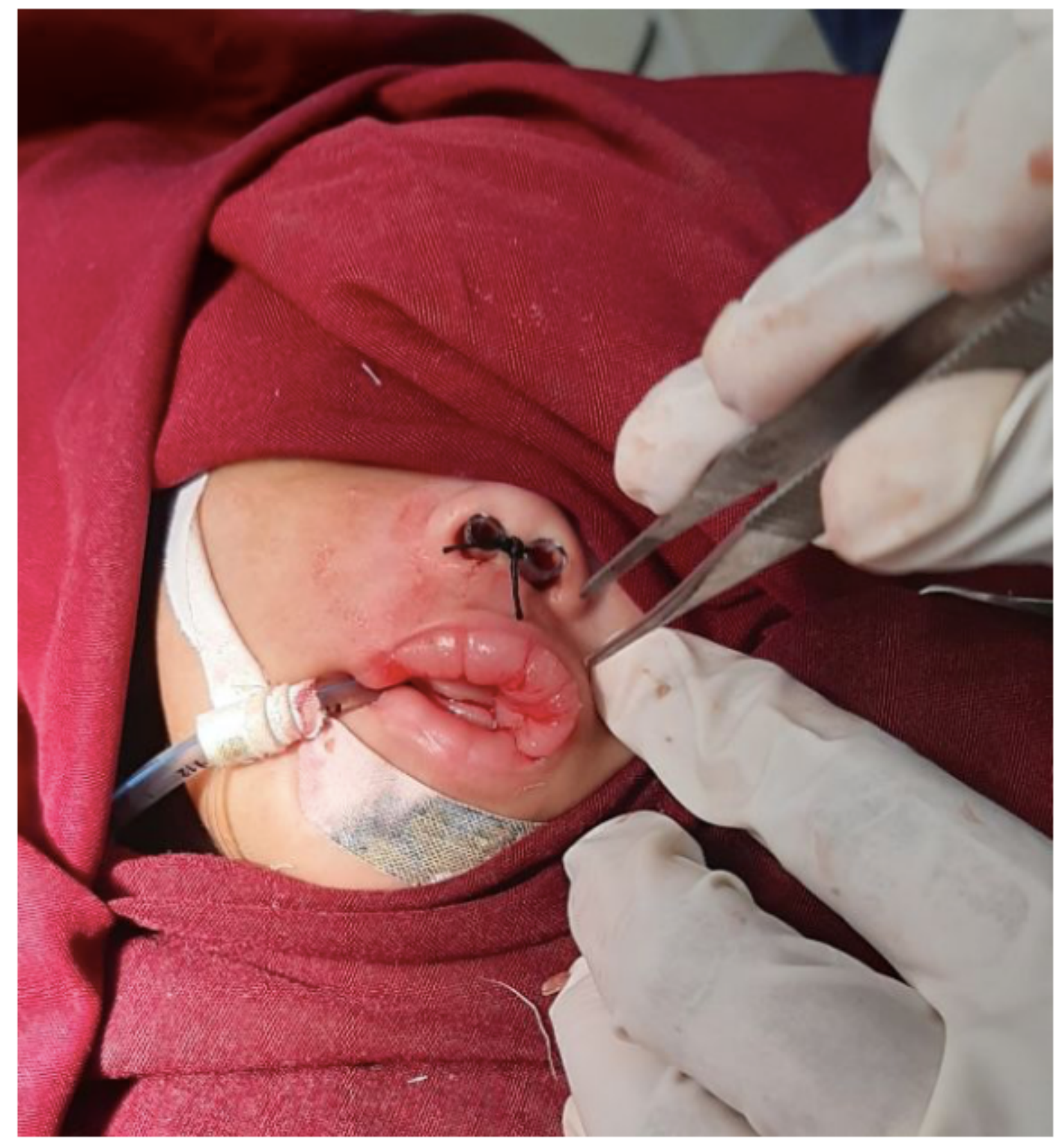

\section{FIGURE 13 NASAL STENT PLACED USING 3.5MM ET AT THE END OF THE PROCEDURE}

Figure 13

Nasal stent placed using $3.5 \mathrm{~mm} \mathrm{ET}$ at the end of the procedure 